\title{
Formulation Design of Indomethacin-Loaded Nanoemulsion For Transdermal Delivery
}

\author{
Nahla Barakat ${ }^{1 *}$, Ehab Fouad ${ }^{1}$ and Azza Elmedany ${ }^{2}$ \\ ${ }^{1}$ Department of Pharmaceutics, College of Pharmacy, King Saud University, Riyadh, Saudi Arabia \\ ${ }^{2}$ Department of Pharmacology, College of Medicine, king Saud University, Saudi Arabia
}

\begin{abstract}
The aim of the present study was to investigate the potential of nanoemulsion formulations for transdermal delivery of indomethacin (IND). Nanoemulsions formulations with different Surfactant: co surfactant ratios (S ${ }_{\text {mix }}$ ); F1-F6 $(1: 1,2: 2,3: 1,4: 1,1: 2$ and $3: 2)$ were prepared by the spontaneous emulsification method, and characterized for morphology using transmission electron microscopy (TEM), droplet size, and rheological characteristics. The ex vivo skin permeation studies were performed using Franz diffusion cell with rabbit skin as permeation membrane. A significant increase in the permeability parameters such as steady-state flux (Jss), permeability coefficient (Kp), and enhancement ratio $(\mathrm{Er})$ was observed in nanoemulsion formulations compared with the conventional IND gel. The anti-inflammatory effects of nanoemulsion formulations showed a significant increase in percent inhibition value after 4 hours when compared with conventional IND gel on carrageenan-induced paw edema in rats. Significant increase in permeability parameters was observed in nanoemulsion formulations $(P<0.05)$. The steady-state flux $\left(J_{\mathrm{ss}}\right)$ and permeability coefficient $\left(K_{\mathrm{p}}\right)$ for optimized nanoemulsion formulation $\left(\mathrm{F}_{1}, 1: 1 \mathrm{~S}\right.$ mix were found to be $22.61 \pm 3.45 \mu \mathrm{g} /$ $\mathrm{cm}^{2} / \mathrm{h}$ and $0.22 \times 10^{-2} \pm 0.0003 \mathrm{~cm} / \mathrm{h}$, respectively), which were significant compared with conventional IND gel and $(P<0.001)$. Enhancement ratio $\left(E_{r}\right)$ was found to be 8.939 in optimized formulation F1 compared with IND gel. These results suggested that nanoemulsions can be used as potential vehicles for improved transdermal delivery of indomethacin as an approach to eliminate the side effect of the oral dose.
\end{abstract}

Keywords: Nanoemulsion; Indomethacin; Surfactant: Co surfactant mixture; Permeability coefficient; Anti inflammatory effect

\section{Introduction}

Nanoemulsions (NE) have received a growing attention as colloidal drug carriers for pharmaceutical applications. Typically, NE consists of oil, surfactant, co surfactant and aqueous phase, which are transparent, thermodynamically stable with a droplet diameter usually within the range of $10-100 \mathrm{~nm}$ and does not have the tendency to coalesce $[23,45]$. Nanoemulsions have several advantages such as enhanced drug solubility, good thermodynamic stability, enhancing effect on transdermal ability over conventional formulation [18,26,41] Moreover, nanoemulsions can accommodate both hydrophilic and lipophilic drugs [19,25,53]

Indomethacin, (IND) is a potent non-steroidal anti-inflammatory drug with analgesic and antipyretic properties. Like other NSAIDs, the most common side effect of indomethacin in oral dosage forms is gastrointestinal irritation. Thus, alternative routes of administration for these drugs are being currently investigated. Recently, more attention has focused on nanoemulsions for transdermal delivery of drugs $[11,16,27,31]$

Transdermal route has been known to eliminate oral gastrointestinal (GI) adverse effects and maintain the plasma drug level for longer period of time and suitable for long treatment of chronic disease. Recent studies have shown significant drug levels in deep tissues such as fascia, muscle and synovium after topical application $[33,40]$ which is a desirable feature for the relief of local symptoms with low dose, thereby reducing systemic side effects.

Nanoemulsions have also shown improved transdermal permeation of many drugs over the conventional topical formulations such as emulsions [17] and gels [38]. Aqueous phase titration or spontaneous emulsification method has been successfully investigated for the preparation of oil-in-water $(\mathrm{o} / \mathrm{w})$ nanoemulsions of many lipophilic drugs [6,34]. Several mechanisms have been proposed to explain the advantages of nanoemulsion for the transdermal delivery of drugs. First, the high solubility potential for drugs of nanoemulsion system might increase thermodynamic activity towards the skin [36]. Second, ingredients of nanoemulsion, acting as permeation enhancers, might increase the flux of drug via skin [37]. Third, the permeation rate of the drug from nanoemulsion may be increased because the affinity of a drug to the internal phase could be modified easily to favor partitioning into stratum cornea $[3,15,52]$ Since nanoemulsions contain surfactant compounds in its composition, the application on the skin surface usually produces an increase in the membrane permeability facilitating transdermal transport $[43,48]$. The literature shows that NE can control release and bioavailability of many drug compounds [21,35,52]. In this study, an optimum topical nanoemulsion containing IND was developed after screening various oils to improve the drug solubility, the skin permeability and the anti-inflammatory effect.

\section{Materials and Methods}

\section{Materials}

Indomethacin (IND) was kindly supplied by Pharma Tech

*Corresponding author: Nahla S. Barakat, Department of Pharmaceutics, College of Pharmacy, King Saud University, P.O. Box: 22452, Riyadh: 11495 , Saudi Arabia, Tel: 966-502963114; Fax: 966-12913735; E-mail: nsybarakat@ yahoo.com

Received September 08, 2011; Accepted November 17, 2011; Published November 19, 2011

Citation: Barakat N, Fouad E, Elmedany A (2011) Formulation Design of Indomethacin-Loaded Nanoemulsion For Transdermal Delivery. Pharm Anal Acta S2:002. doi:10.4172/2153-2435.S2-002

Copyright: ( 2011 Barakat N, et al. This is an open-access article distributed under the terms of the Creative Commons Attribution License, which permits unrestricted use, distribution, and reproduction in any medium, provided the original author and source are credited. 
(Ireland). PEG-8 caprylic/capric glycerides (Labrasol $\left.{ }^{\circledR}\right)$, diethylene glycol monoethyl ether (Transcutol ${ }^{\circledR} \mathrm{P}$ ), propylene glycol monolaurate (Lauroglycol 90), Labrafil M 2155 CS, Labrafil M 1944 were kindly donated by Gattefosse, France. Isopropyl myristate (IPM), soya bean oil, cotton seed oil (Sigma Chemical Co., St. Louise, USA). Acetonitrile, ethanol and methanol used were of HPLC grade. Oleic acid, polyoxyethylene sorbitan trioleate (Tween 85), polyethylene glycol 600 were purchased from Sigma Chemical Co., USA. Commercial indomethacin gel: Farcomethacin $1 \%$ gel, batch no: 380, (Pharco Pharmaceuticals, Alexandria, Egypt). Cellulose membrane cut off 12000D, Biogen, Belgium (Sigma Chemical Co., St. Louise, USA). All other chemical and solvents were of analytical reagent grade.

Rabbit ears were collected immediately after sacrifice from a local slaughterhouse. The skin from rabbit was excised from freshly killed male New Zealand white rabbits for human alimentation [7]. The average thickness of the skin was $0.38 \pm 0.06 \mathrm{~mm}$.

\section{Screening of oils and surfactants for nanoemulsion}

In order to find out appropriate oils and surfactants that had good solubilizing capacity of IND and, thus, could be used as the oil phase and surfactants in nanoemulsion, the solubility of IND in various oil and surfactant were measured. Oils employed were soya bean oil, isopropyl myristate (IPM), labrafil 2155, labrafil 1944, Labrafac lipofile and oleic acid. Surfactants employed were Tween 80 , Tween 20 and Labrasol, co surfactant was Transcutol P. The solubility of IND in various oils and surfactants was determined using the shake flask method. Briefly, an excess amount of IND was placed in $2 \mathrm{ml}$ of the vehicle in screw capped glass vials. After sealing, the mixture was vortexed using a cyclomixer for $10 \mathrm{~min}$ in order to facilitate proper mixing of IND with the vehicles. Mixtures were shaken for $72 \mathrm{~h}$ in an isothermal shaker (GFL, Model 1083 , and Germany) maintained at $20 \pm 1{ }^{\circ} \mathrm{C}$. Mixtures were centrifuged at $12,000 \mathrm{rpm}$ for $15 \mathrm{~min}$. The supernatant was filtered through membrane filter (Nylon, $0.45 \mu \mathrm{m}$, Gelman, USA), and then probably diluted with methanol. The concentration of IND in the supernatant was determined by high-performance liquid chromatography (HPLC) method as described below. Based on these results, appropriate oil, surfactant and co surfactant were selected and used in the preparation of nanoemulsions containing 1\% IND. The effect of the mixture of surfactant and co surfactant on the permeation of IND through excised rabbit skin was evaluated.

\section{Construction of pseudo-ternary phase diagrams}

Pseudo-ternary phase diagrams were constructed using water titration method at ambient temperature to obtain the components and their concentration ranges that could result in large existence area of nanoemulsion without the drug [16]. On the basis of the solubility studies, IPM was selected as an oil component and Labrasol as a surfactant, Transcutol P as a co surfactant, in the ME systems. Six phase diagrams were prepared at different surfactant/co surfactant ratios $\left(\mathrm{S}_{\text {mix }}\right)$ of $4 / 1,3 / 1,2 / 1,1 / 1,1 / 2$ and $3 / 2$. For each phase diagram, oil and $\mathrm{S}_{\text {mix }}$ were combined in different weight ratios. The ratio of oil to the mixture of the surfactant and the co surfactant was varied as 5, 10, 20, $30,40,50$, and $60 \%$. The IND-containing formulations were prepared by dissolving $20 \mathrm{mg}$ of the drug into $2 \mathrm{~g}$ of the oily mixtures. Water was added drop by drop using a micropipette. No heating was necessary during the preparation. However, the system was stirred using a magnetic stirrer to ensure a thorough mixi [26] ng. The nanoemulsion regions were identified as transparent and isotropic mixtures. After each mixing, the sample was allowed to settle and its physical condition (clarity and flowability) was reviewed. The point at which the mixture became turbid or showed signs of phase separation was considered as the end point of the titration. If required, the sample was sonicated for 1 to 2 minutes to remove air bubbles and to enable a better visual examination. Mixtures that did not show a change in the meniscus after tilting to an angle of $90^{\circ} \mathrm{C}$ were considered to be gels. After being equilibrated, the mixtures were assessed visually and determined as being nanoemulsions, crude emulsions or gels. The concentrations of components were recorded in order to complete the pseudo-ternary phase diagrams, and then the contents of oil, surfactant, co surfactant and water at appropriate weight ratios were selected based on these results. No attempt was made to distinguish between o/w, w/o or bicontinuous type nanoemulsions.

\section{HPLC analysis of IND}

The solubility of IND in various excipients was determined by a validated reverse-phase HPLC method. The HPLC apparatus (Shimadzu VP series) equipped with System controller (SCL-10 A VP, Shimadzu); UV-Vis Spectrophotometer detector (SPD-10 A VP, Shimadzu, Japan), a Rheodyne sample injector (Rheodyne, USA) with $50 \mu \mathrm{l}$ sample loop and Bondapak $\mathrm{C}_{18}(4.6 \mathrm{~mm}$ (id) $\times 150 \mathrm{~mm}$ and 5 - $\mu \mathrm{m}$ particle size) column. The mobile phase consisted of a mixture of acetonitrile:water ( $\mathrm{pH}$ was adjusted to 3.2 with orthophosphoric acid) $(60: 40 \mathrm{v} / \mathrm{v})$ at a flow rate of $1.5 \mathrm{ml} / \mathrm{min}$ that led to a retention time of $3.5 \mathrm{~min}$ when detection was carried out at $260 \mathrm{~nm}$. The assay was linear $\left(r^{2}=0.9996\right)$ in the concentration range $0.5-10 \mu \mathrm{g} / \mathrm{ml}$ with the lowest detection limit of $200 \mathrm{ng} / \mathrm{ml}$ of IND. The method was validated with respect to accuracy and inter- and intra-day precision as per ICH guidelines. The validation studies showed overall intra- and interday variations (RSD) of less than $3.1 \%$ and $8.2 \%$, respectively. The percentage difference between amounts determined and spiked was considered to be a measure of accuracy. An accuracy of 98.7-112.0\% was obtained for each of the analytes tested, and RSD was $<9.8 \%$.

\section{Preparation of nanoemulsion formulations}

From the constructed pseudo-ternary phase diagrams, different formulas were selected from the nanoemulsion region as described in Table 2, so that the drug could be incorporated into the oil phase. Exactly $1 \% \mathrm{w} / \mathrm{w}$ of IND, which was kept constant in all the selected formulations, was dissolved in the oil phase of the nanoemulsion formulation.

\section{Characterization of the nanoemulsions}

Viscosity Measurements: The viscosity of emulsions was measured on a Brookfield R/S plus Rheometer equipped with Rheocalc V1.1 software, (Brookfield Engineering Laboratories Inc. Massachusetts, USA). C50- 1 Cone and plate geometry was used with $50 \mathrm{~mm}$ diameter and cone of $1.0^{\circ} \mathrm{C}$. The temperature was controlled and kept constant at room temperature $\left(20^{\circ} \mathrm{C} \pm 0.2^{\circ} \mathrm{C}\right)$ using a model TC-500 thermostat Braive Instruments, Liege, Belgium). The volume of sample was $1 \mathrm{~mL}$ at $150 \mathrm{rpm}$.

Morphology of nanoemulsion: Morphology and structure of the nanoemulsion were studied using transmission electron microscopy, TEM, (JEOL-1011, Electron Microscope, Japan) operating at 200 $\mathrm{kV}$ and capable of point-to-point resolution. To perform the TEM observation, a drop of sample was directly deposited and dried on the TEM copper grid, and then coated with carbon film under the ambient condition $\left(22^{\circ} \mathrm{C}\right)$. The samples were determined at $100 \mathrm{Kv}$.

In vitro release studies: The release experiments employed the FDC- 
6 transdermal Diffusion Cell Drive Console (Logan Instrument Corp., NJ, and USA). The apparatus consisted of clamped preconditioned synthetic membrane (cellulose; MW: 12,000) on to glass diffusion cell between donor and receptor compartments. The receptor compartment was filled with $12 \mathrm{ml}$ of $20 \%$ alcohol in $0.02 \mathrm{M}$ phosphate buffer at pH 7.4 [51]. The receptor solutions were magnetically stirred at 600 rpm throughout the experiment. The diffusion cell was maintained at $37^{\circ} \mathrm{C}$ using a re-circulating water bath (Julabo, Germany). The donor compartment was one gram of prepared nanoemulsion containing IND $(1 \% \mathrm{w} / \mathrm{w})$, and the donor cap was covered with a parafilm and clamped. Sampling port was sealed with a parafilm to prevent the evaporation of the receptor medium. Five $\mathrm{mL}$ aliquots withdrawn from the receptor compartment at various intervals for $24 \mathrm{~h}$ were filtered through 0.45 $\mu \mathrm{m}$ and IND was quantified using HPLC method as described above. The receptor compartment was refilled with the same volume of fresh buffer solutions. Three replicates of each experiment were performed. Sink conditions were maintained in the receptor compartment during in vitro permeation studies.

\section{In vitro skin permeation study}

Preparation of skin samples: All animal procedures were conducted in accordance with approved institutional protocols. The rabbit ear model was adopted to monitor the skin delivery of a variety of drugs including lipophilic ones similar to our drug [47]. Full thickness skin obtained from the inner side of freshly excised ears of 6 male rabbits, weighing $2-3 \mathrm{~kg}$ was used. The average thickness of the skin was $0.28 \pm 0.06 \mathrm{~mm}$. Skins were allowed to hydrate for $1 \mathrm{~h}$ before being mounted on the Franz-type diffusion with the stratum corneum facing the donor compartment and the dermal side faced the receiver compartment.

Skin permeation studies: The extent and rate of skin permeation of IND from nanoemulsions of various compositions were determined using Franz diffusion cells fitted with excised rabbit skins. The effective diffusion area was $1.77 \mathrm{~cm}^{2}$. The receiver medium constituted of $20 \%$ alcohol in $\mathrm{pH} 7.4$ phosphate buffer $(0.02 \mathrm{M})$ was continuously stirred with a small magnetic bar and thermostated at $37 \pm 1{ }^{\circ} \mathrm{C}$, so that the skin surface temperature was approximately at $32 \pm 1^{\circ} \mathrm{C}$. One gram of the formulation was placed on the skin surface in the donor compartment. After application of the test formulation on the donor side, $5 \mathrm{ml}$ aliquots were collected from the receptor side at designated time intervals, for a $24 \mathrm{~h}$ period, and replaced by the same volume of fresh buffer to maintain a constant volume. The amount of IND in the receiver phase was assayed by HPLC. Each data point represents the average of three determinations.

Analysis of permeation data: Cumulative amounts of drug (mg) penetrating the unit diffusion surface $\left(\mathrm{cm}^{2}\right)$ was plotted against time (h). The in vitro skin permeation rate or flux $(J)$ was calculated from the slope of the regression line fitted to the linear portion of the profile. Extrapolation of this line will intercept with the $\mathrm{x}$-axis at a time equal to the lag time. The permeability coefficient, $\mathrm{k}_{p}$, was estimated from the flux and donor drug concentration. Penetration enhancing activities compared with the conventional IND gel are expressed as enhancement ratio (Er).

The cumulative drug permeation $\left(Q_{t}\right)$ was calculated from the following equation:

$$
Q_{t}=V_{\mathrm{r}} C_{t}+\sum_{\mathrm{i}=0}^{\mathrm{t}-1} V s \mathrm{C}_{\mathrm{i}}
$$

Where $C_{t}$ is the drug concentration of the receiver solution at each sampling time, $C_{i}$ the drug concentration of the $i$ th sample, and $V_{\mathrm{r}}$ and $V_{\mathrm{s}}$ the volumes of the receiver solution and the sample, respectively, Data were expressed as the cumulative IND permeation per unit of skin surface area,

$\mathrm{Q}_{\mathrm{t}} / \mathrm{S}\left(\mathrm{S}=1.767 \mathrm{~cm}^{2}\right)$. The steady-state fluxes $\left(J_{S S}(2-10 \mathrm{~h})\right)$ were calculated by linear regression interpolation of the experimental data at steady state (between 2 and $10 \mathrm{~h}$ ):

Apparent permeability coefficients $\left(\mathrm{K}_{p}\right)$ were calculated according to the equation:

$$
\mathrm{K}_{p}=J \mathrm{ss} / \mathrm{C}_{\mathrm{o}}
$$

where $\mathrm{C}_{\mathrm{o}}$ is the drug concentration in the donor solution $\left(1 \times 10^{4} \mu \mathrm{g} /\right.$ $\mathrm{cm}^{3}$ ), while assuming that under sink conditions the drug concentration in the receiver is negligible compared to the drug in the donor.

The data are presented as means \pm SD obtained using $4-8$ skin fragments from at least two animals.

Enhancement ratio (Er) was calculated by dividing the Jss of respective formulation with Jss of control formulation by using the equation:

$$
\underline{\mathrm{Er}=J \text { ss of formulation }}
$$

Jss of control

Anti-inflammatory effect of the IND nanoemulsion on carrageenan-induced paw-edema in rats: Paw edema can be induced by murine carrageenan. Male Sprague-Dawley rats weighing 150-180 g were used for the experiments. The animal study protocol was reviewed and approved by the Animal Ethics Committee of the University of King Saud, Riyadh. All measurements were performed at $24 \pm 1^{\circ} \mathrm{C}$ in an air-conditioned room. The animals were randomly divided into 8 groups of six rats for administration. The rats of the first control group were treated with normal saline [1]. The other seven experimental groups received different topical formulations of IND nanoemulsions and the commercial IND gel. To induce local inflammation, $50 \mu \mathrm{l}$ of $1 \%$ carrageenan $(\mathrm{w} / \mathrm{v})$ in saline was injected into the plantar surface of the left hind paw of the rats at time zero, using a 27-gauge needle coupled to a $100 \mathrm{ml}$ Hamilton syringe. In the first experiment, $60 \mathrm{~min}$ later, $100 \mathrm{mg}$ of IND nanoemulsion or IND gel was applied, nonocclusively, to the paws of the animals and spread gently. Animals were then housed in polypropylene cages with framed metal mesh on the floor to prevent absorption of applied products by sawdust. The animals were maintained without access to food and water during the experiment.

All experiments were carried out between 9.00 a.m. and 3.00 p.m. Measurements of foot volume were performed by the method described by [45] using water plethysmometer (LE 7500, Letica Scientific Instruments, Barcelona, Spain) before and 1, 2, 3, 4, and $5 \mathrm{~h}$ after the injection of carrageenan into the planter region of the left hind paw. The degree of paw swelling was calculated as:

$$
\text { Swelling }(\%)=\frac{V_{\mathrm{i}}-V_{0}}{V_{0}} \times 100
$$

Where $V_{\mathrm{i}}(\mathrm{ml})$ is the volume of the carrageenan-treated paw, $V_{0}$ is that of the non-treated paw.

On the basis of Eq. (4), the percentage edema inhibition was calculated as:

Inhibition $(\%)=\frac{\% \text { Swelling of nanoemulsion }- \text { treated group }}{\% \text { swelling of control group }} \times 100$ 


\section{Results and Discussion}

\section{Screening components for nanoemulsion}

The consideration for screening formulation of nanoemulsions usually involves: the formulation composition should be simple, safe and compatible; it should possess good solubility; a large efficient region which should be found in the pseudo ternary phase diagram, and have efficient droplet size after forming nanoemulsion [42].

In order to screen appropriate solvents for the preparation of nanoemulsions, the solubility of IND in various oil and surfactants were measured and the results were shown in Table 1 . The solubility of IND was highest in IPM followed by soyabean oil, Labrafil 2155, Labrafil 1944, Lauroglycol and oleic acid. Previous reports indicated that the superior dermal flux appeared mainly due to the large solubilizing capacity of the nanoemulsions, which led to larger concentration gradient towards the skin [24]. Isopropyl myristate had wide pharmaceutical applications owing to its good biological acceptance $[10,46]$. IPM was an excellent enhancer in transdermal delivery as previously reported [28] and it was selected as the oil phase. Takahashi et al., 1991 found that the skin permeation was inhibited as the affinity to vehicle become greater due to a slow release of the drug and/or a poor transfer from the vehicle to the skin. Li et al., $2004 \mathrm{a}, \mathrm{b}$ had reported that the dermal drug permeation is influenced primarily by the solubility of drug in vehicle and the partition coefficient of skin/ vehicle. IND has the highest solubility in IPM hence it was selected as oil phase. IND also had a higher solubility in Labrasol $(178.32 \mathrm{mg} / \mathrm{g})$ and Transcutol P (185.52 mg/g) followed by propylene glycol (117.48 $\mathrm{mg} / \mathrm{g})$ and Tween $80(110.65 \mathrm{mg} / \mathrm{g})$. Cosurfactants can decrease interfacial tension between oil and water in nanoemulsion, adjust the flexibility of interfacial membrane and reduce the required amount of surfactant sometimes. The short-chain alcohols and transcutol $\mathrm{P}$ were widely used as co surfactant $[28,38]$. Transcutol P seems to be very attractive as a penetration enhancer due to its non-toxicity, biocompatibility with the skin, miscibiliity with polar and non-polar solvents and optimal solubilizing properties for a number of drugs [5]. Therefore, Labrasol and Transcutol $P$ were selected as surfactant and co surfactant, respectively, for the phase study. The right blend of

\begin{tabular}{|l|l|l|l|}
\hline Excipients & $\begin{array}{l}\text { Solubility } \\
\text { Mean } \pm \text { SD } \\
(\mathrm{mg} / \mathrm{g})\end{array}$ & Excipients & $\begin{array}{l}\text { Solubility Mean } \pm \\
\text { SD }(\mathrm{mg} / \mathrm{g})\end{array}$ \\
\hline Soya bean oil & $13.87 \pm 2.65$ & Labrafac & $27.34 \pm 5.83$ \\
\hline Oleic acid & $3.45 \pm 1.98$ & Labrasol & $178.32 \pm 5.32$ \\
\hline Isopropyl myristate & $32.65 \pm 4.3$ & Propylene glycol & $117.48 \pm 3.21$ \\
\hline Labrafil 2155 & $10.23 \pm 1.87$ & Polyethylene glycol 400 & $107.34 \pm 3.69$ \\
\hline Labrafil 1944 & $7.86 \pm 1.98$ & Transcutol P & $185.52 \pm 4.57$ \\
\hline Lauroglycol & $8.28 \pm 2.09$ & Tween 80 & $110.65 \pm 3.82$ \\
\hline
\end{tabular}

Table 1: Solubility of IND in various excipients $(n=3)$.

\begin{tabular}{|c|c|c|c|c|c|}
\hline $\begin{array}{l}\text { Formulation } \\
\text { Code }\end{array}$ & $\begin{array}{l}S / \text { Co } S \\
\left(S_{\text {mix }}\right) \text { ratio }\end{array}$ & $\begin{array}{l}\% \mathrm{w} / \\
\text { nano }\end{array}$ & $\begin{array}{l}\text { nponents in } \\
\text { n formulatic }\end{array}$ & & Oil:S ${ }_{\text {mix }}$ ratio \\
\hline & & Oil & $\mathrm{S} / \mathrm{Co} \mathrm{S}_{\text {mix }}$ & water & \\
\hline F1 & 1:1 & 43.2 & 43.2 & 13.6 & 1.0 \\
\hline F2 & $2: 1$ & 42.0 & 42.0 & 16 & 1.0 \\
\hline F3 & 3:1 & 33.9 & 50.0 & 16.1 & 0.678 \\
\hline F4 & $4: 1$ & 37.0 & 46.0 & 17 & 0.804 \\
\hline F5 & 1:2 & 41.6 & 41.6 & 16.8 & 1.0 \\
\hline F6 & $3: 2$ & 40.6 & 50.7 & 8.7 & 0.757 \\
\hline
\end{tabular}

Table 2: Composition of selected nanoemulsion formulations.
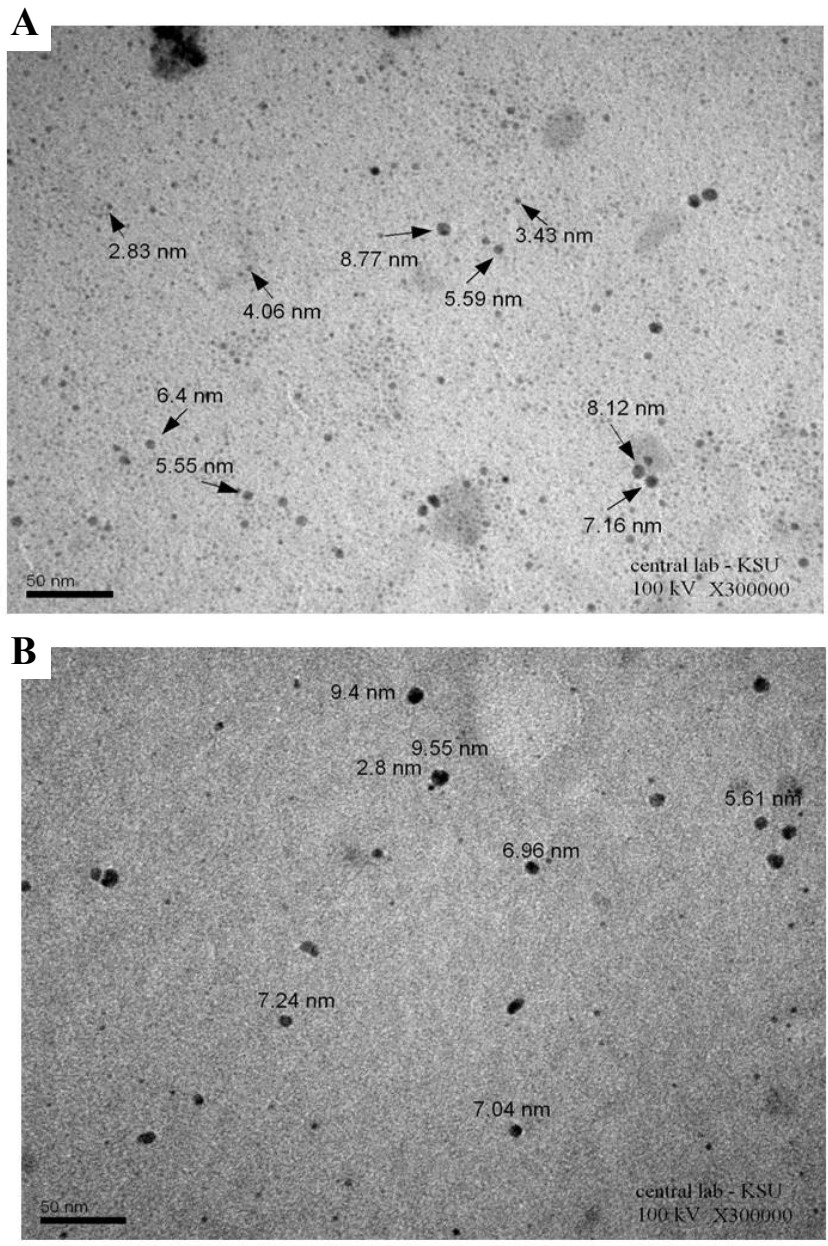

Figure 1: Transmission electron microscopic positive image of IND nanoemulsion showing the size of some oil droplets $(300,000 x)$.

low and high hydrophilic lipophilic balance (HLB) surfactants leads to the formation of stable nanoemulsion formulations [14]. In this study, we selected Labrasol as a surfactant with an HLB value of 14, and Transcutol P with a low HLB value (4.2).

Characterization of the nanoemulsions: With the measurement of transmission electron microscope, the optimized nanoemulsion vesicles appeared as perfect round shape without aggregation (Figure 1). The characteristics of nanoemulsions such as droplet size and viscosity measurements were given in Table 3 . The parameters for physicochemical characters of the optimized formulations were as follows: $3.74-16.43 \mathrm{~nm}$ for the average size of all nanoemulsion vehicles particle size. All the droplets were found in the nanometer range which indicated the suitability of formulation for transdermal drug delivery. Polydispersity signifies the uniformity of droplet size within the formulation. The polydispersity value of the formulations was very low $(<0.2)$ which indicated uniformity of droplet size within the formulation. The viscosity of the selected nanoemulsion was determined (Table 3). The viscosity of formulation $\mathrm{F}_{1}(11.875 \mathrm{cP})$ was lower than that of other formulation; this difference was significant $(P$ $<0.05$ ) compared with $\mathrm{F}_{2}, \mathrm{~F}_{3}, \mathrm{~F}_{4}$, and $\mathrm{F}_{6}$. The viscosity of formulation $\mathrm{F}_{4}$ was highest (33.361 cP). Generally, it was observed that the viscosity of the nanoemulsion formulations was very low. Lower viscosity is one of the characteristics of nanoemulsion formulations [26]. 
Citation: Barakat N, Fouad E, Elmedany A (2011) Formulation Design of Indomethacin-Loaded Nanoemulsion For Transdermal Delivery. Pharm Anal Acta S2:002. doi:10.4172/2153-2435.S2-002

Page 5 of 8

\begin{tabular}{|c|c|c|c|c|c|}
\hline Formulation code & F 1 & F 2 & F 3 & F 4 & F 5 \\
\hline Ratio S/ Co S & $1: 1$ & $2: 1$ & $3: 1$ & $4: 1$ & $3: 2$ \\
\hline Average droplet size (nm) & $5.74 \pm 0.55$ & $6.98 \pm 0.62$ & $8.54 \pm 0.65$ & $9.43 \pm 0.78$ & $7.43 \pm 0.86$ \\
\hline Polydispersity index & 0.096 & 0.088 & 0.076 & 0.083 & 0.075 \\
\hline Viscosity (mPas) & $11.875 \pm 4.1$ & $23.451 \pm 2.9$ & $26.116 \pm 2.9$ & $33.361 \pm 2.8$ & $12.534 \pm 3.7$ \\
\hline
\end{tabular}

Table 3: The S/Co S $\left(\mathrm{S}_{\text {mix }}\right)$ ratios, average droplet size, Polydispersity values and viscosity of IND nanoemulsion formulations.

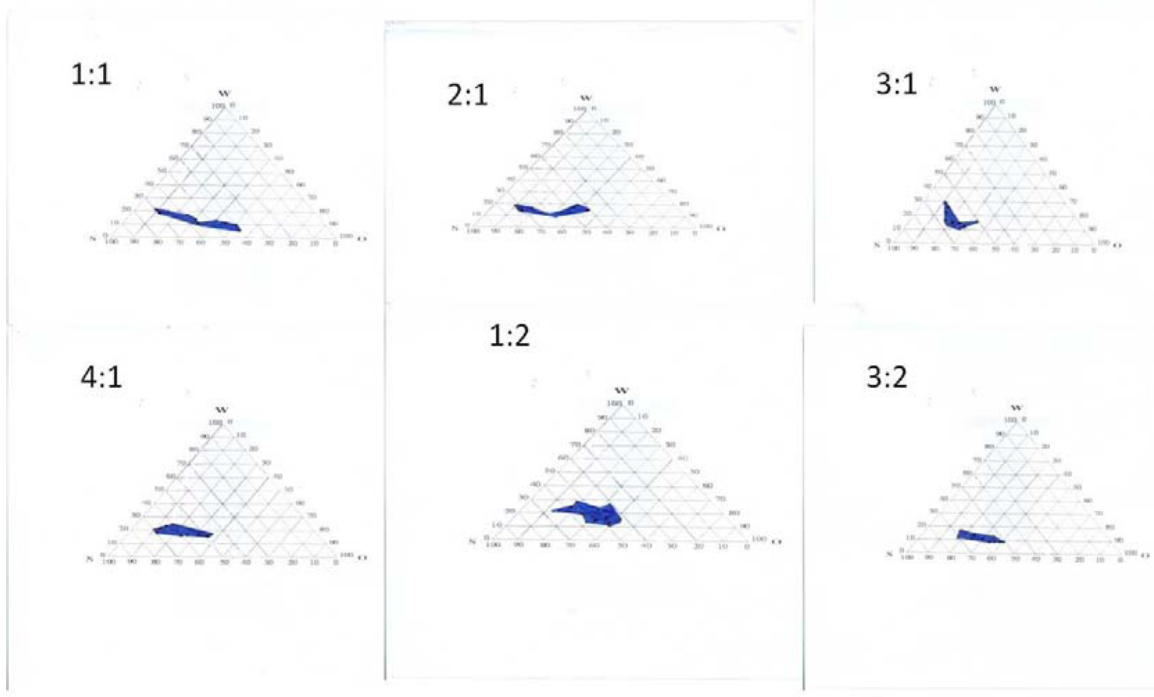

Figure 2: Pseudo-ternary phase diagrams of nanoemulsion composed of isopropyl myristate, surfactant (Labrasol), co-surfactant (Transcutol P) and water at different $\mathrm{S}_{\text {mix }}$

All nanoemulsion formulations were stable at ambient temperature in the presence or absence of IND. No changes of particle size, phase separation and degradation of IND were observed during 6 months. The centrifuge tests showed that all nanoemulsion systems had good physical stability.

Construction of pseudo-ternary diagrams: The construction of pseudo-ternary phase diagrams was used to obtain appropriate concentration ranges of components in the areas of forming nanoemulsions. The pseudo-ternary phase diagrams of nanoemulsions composed of IPM, Labrasol, Transcutol P and distilled water with various $\mathrm{S}_{\text {mix }}$ values were shown in Figure 2. The area region of nanoemulsions became enlarged as $\mathrm{S}_{\text {mix }}$ decreased, reaching the maximum point at $\mathrm{S}_{\text {mix }}$ of $1: 2$.

In vitro permeation study: Figure 3 shows the mean cumulative amount of IND released from nanoemulsion formulations through the cellulose membrane compared with the conventional IND gel. The figure showed a linear relationship as long as sink conditions were maintained, indicating nearly zero order release kinetics. The drug flux ranged from $21.212 \mu \mathrm{gcm}^{-2} \mathrm{~h}^{-1}\left(\mathrm{~F}_{4}\right)$ to $46.796 \mu \mathrm{gcm}^{-2} \mathrm{~h}^{-1}\left(\mathrm{~F}_{6}\right)$, while the drug permeated from IND gel laying in an immediate position $(32.030$ $\left.\mu \mathrm{gcm}^{-2} \mathrm{~h}^{-1}\right)$. Short initial lag times were observed, almost independent of nanoemulsion composition and /or drug flux variations, indicating that pseudo-steady state conditions were quickly achieved in all cases [22].

Ex vivo permeation studies: The results of permeation experiments from rabbit ear skin are shown in Figure 4. As expected, the drug penetration rate through excised rabbit ear skin was slower than that through artificial cellulose membrane and longer times were necessary to establish a uniform concentration gradient within the membrane and reach the quasi-stationary state. In fact, the early portion of all the permeation curves showed a more or less evident convexity to the time axis, typical of non-steady state conditions, which was followed by an essentially linear profile. The permeability coefficient $(k p)$ and maximum flux $\left(J_{s s}\right)$ of IND were calculated by fitting Equation $(1,2)$ to the permeated and accumulated amounts of drug versus time $(<24$ h) (Table 4). The correlation coefficient $(r)$ of the fit ranged between 0.9878 and 0.9978 . The mean permeability coefficient ranged between

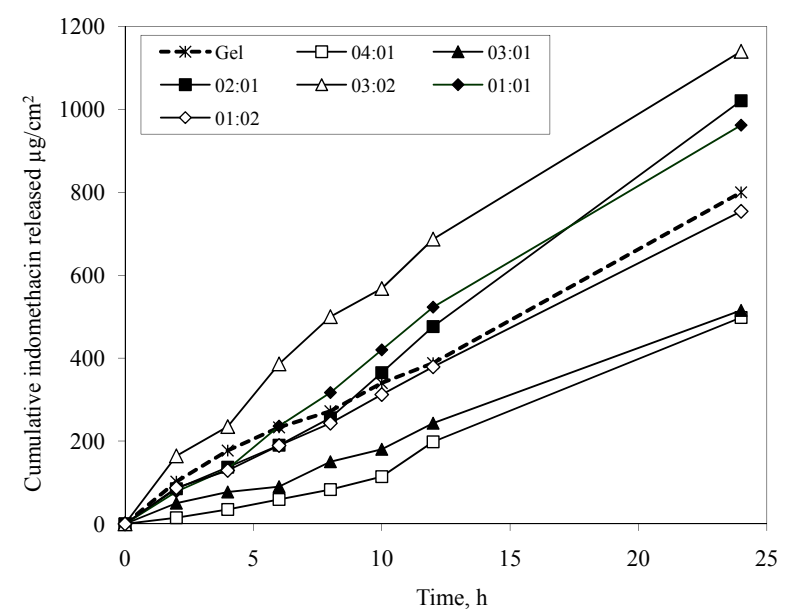

Figure 3: In vitro permeation profiles of IND through cellulose membrane from $1 \%$ IND nanoemulsion formulations with different S/Co $S$ ratios and IND gel. Each point shows the means of three determinations \pm SD. 
$0.22 \times 10^{-2} \mathrm{~cm} \mathrm{~h}^{-1}\left(\mathrm{~F}_{1}\right)$ and $0.11 \times 10^{-2} \mathrm{~cm} \mathrm{~h}^{-1}\left(\mathrm{~F}_{4}\right)$, the maximum flux ranged between $22.608 \mathrm{mgcm}^{-2} \mathrm{~h}^{-1}\left(\mathrm{~F}_{1}\right)$ and $10.736 \mathrm{mgcm}^{-2} \mathrm{~h}^{-1}\left(\mathrm{~F}_{4}\right)$. While the conventional IND gel showed $2.529 \mathrm{mgcm}^{-2} \mathrm{~h}^{-1}, 0.02 \times 10^{-2}$ $\mathrm{cm} \mathrm{h}^{-1}$, respectively. The rank of degree of permeation based on drug permeated at $24 \mathrm{~h}$ (Figure 5) is $\mathrm{F}_{1}>\mathrm{F}_{6}>\mathrm{F}_{2}>\mathrm{F}_{5}>\mathrm{F}_{3} \cong \mathrm{F}_{4}$ IND gel.

From the permeation data, it was found that nanoemulsions could improve the skin permeation of IND over the commercial gel. As reported previously, the thermodynamic activity which can be described as viscosity is important to the permeation into skin. It is known that the viscosity of nanoemulsions is much lower than that of gel, so the mobility of drug in nanoemulsions is more facile. Furthermore, the nanoemulsions may affect the stratum corneum structure and reduce the diffusional barrier by acting as a permeation enhancer $[8,9,32]$. The amount of drug permeated at $24 \mathrm{~h}$ ranged between $480.24 \mu \mathrm{g}\left(\mathrm{F}_{1}\right)$ and $245.83 \mu \mathrm{g}\left(\mathrm{F}_{4}\right)$, compared with $60 \mu \mathrm{g}$ from IND gel. The results showed significance difference $(P<0.001)$. The high permeation rate of nanoemulsions might attribute to several factors. Firstly, the high concentration (1\%) of IND in nanoemulsions resulted in high concentration gradient, which might be the main permeation mechanism of IND into the skin from these nanoemulsions. Nanoemulsions could act as drug reservoirs where drug is released from the inner phase to the outer phase and then further onto the skin [36]. Secondly, due to the small droplet size, some droplets may settled down to close contact with the skin and a large amount of inner

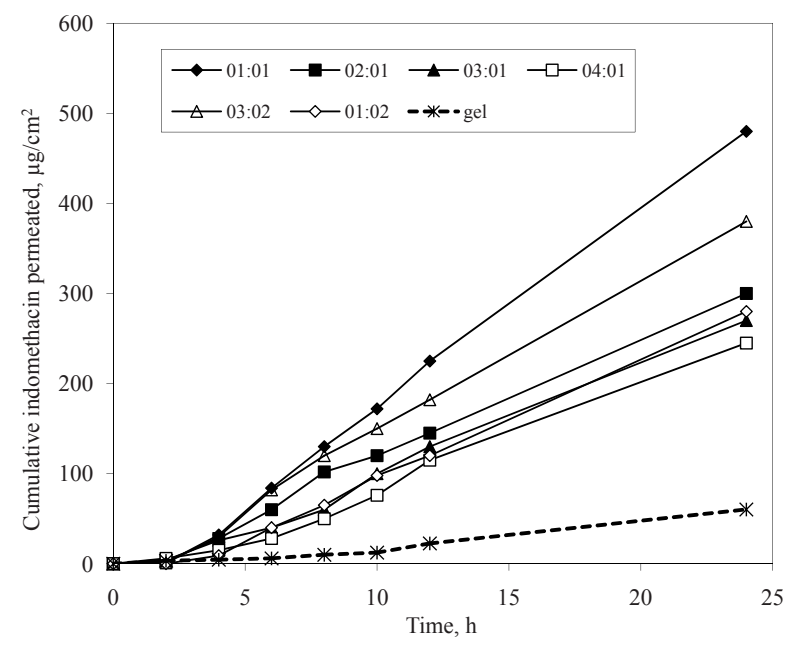

Figure 4: In vitro permeation profiles of IND through excised rabbit skin from $1 \%$ IND nanoemulsion formulations with different S/Co $S$ ratios and IND gel. Each point shows the means of three determinations $\pm S D$.

\begin{tabular}{|c|c|c|c|c|c|c|}
\hline $\begin{array}{c}\text { Formulation } \\
\text { code }\end{array}$ & F1 & F2 & F 3 & F 4 & F 5 & F 6 \\
\hline Ratio S/ Co S & $1: 1$ & $2: 1$ & $3: 1$ & $4: 1$ & $1: 2$ & $3: 2$ \\
\hline $\begin{array}{c}\text { Average } \\
\text { droplet size } \\
\text { (nm) }\end{array}$ & $5.74 \pm 0.55$ & $6.98 \pm 0.62$ & $8.54 \pm 0.65$ & $9.43 \pm 0.78$ & $7.43 \pm 0.86$ & $5.94 \pm 0.89$ \\
\hline $\begin{array}{c}\text { Polydispersity } \\
\text { index }\end{array}$ & 0.096 & 0.088 & 0.076 & 0.083 & 0.075 & 0.148 \\
\hline $\begin{array}{c}\text { Viscosity } \\
\text { (mPas) }\end{array}$ & $11.875 \pm 4.1$ & $23.451 \pm 2.9$ & $26.116 \pm 2.9$ & $33.361 \pm 2.8$ & $12.534 \pm 3.7$ & $18.598 \pm 3.98$ \\
\hline
\end{tabular}

*Means $P<0.0001$ compared with the commercial IND gel

** Enhancement ratio compared with the commercial IND gel

Table 4: Penetration flux, lag time, permeability coefficient, enhancement ratio and correlation coefficient of regression analysis of release data according to Zero order model.

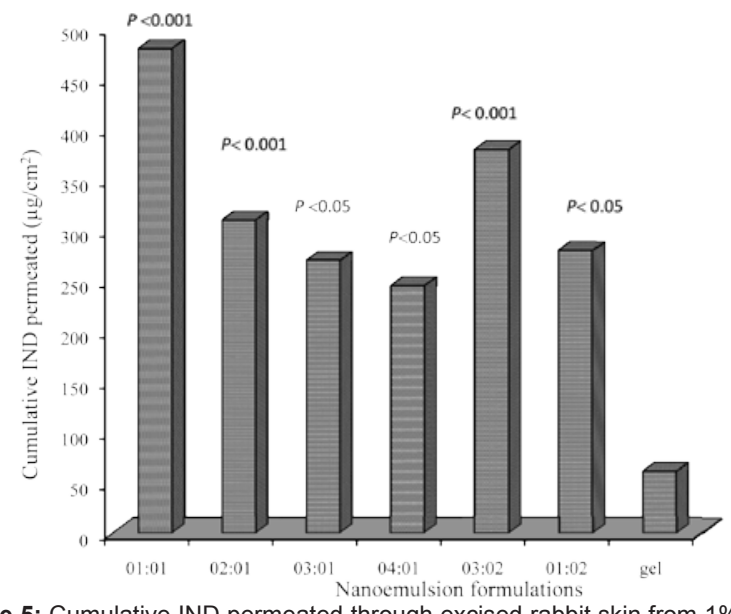

Figure 5: Cumulative IND permeated through excised rabbit skin from 1\% IND nanoemulsion fromulations and IND gel after $24 \mathrm{~h}$. The results are the mean $\pm \mathrm{SD}$ of three experiments. $P$ values compared with the conventional IND gel.

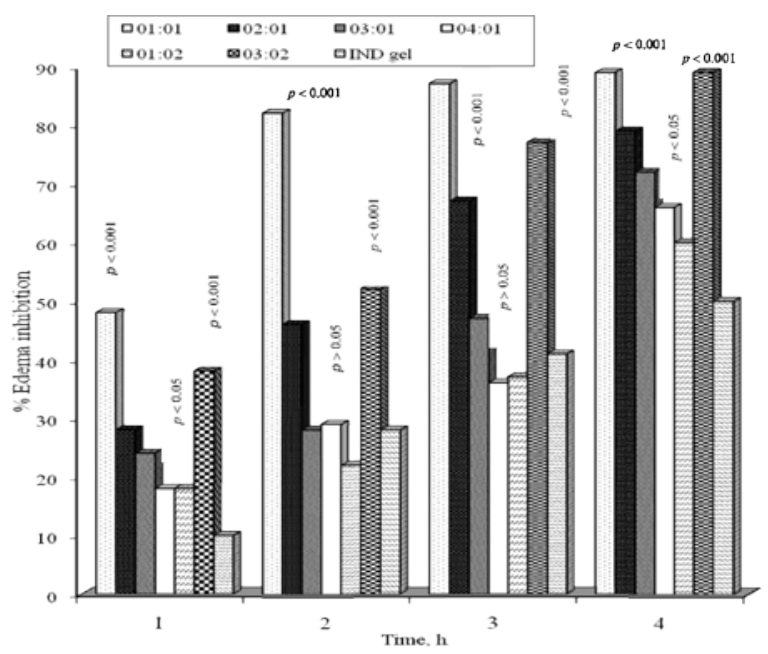

Figure 6: Anti-edema effect of IND nanoemulsion and IND gel as determined $1,2,3$, and $4 \mathrm{~h}$ after intraplantar carrageenan injection using rat paw swelling methods. Results are the mean $\pm \mathrm{SD}$ of six rats. $P$ values compared with the conventional IND gel.

IPM in nanoemulsions might penetrate into skins [13]. Transcutol P primarily act as cosolvent, promoting IND release from the dosage form by increasing the solubility. Therefore the concentration gradient of the drug in solution was increased and favoring the passage of larger quantities of the drug into the stratum corneum was favored. Also, Transcutol $\mathrm{P}$ allows greater solubilization in the aqueous phase of the skin tissues $[2,4]$.

Anti-inflammatory study: Carrageenan-induced hind paw edema is the standard experimental model of acute inflammation. Carrageenan is the phlogistic agent of choice for testing inflammatory drugs as it is not known to be antigenic and is devoid of apparent systemic effects. Moreover, the experimental model exhibits a high degree of reproducibility [50]. The anti-inflammatory effect of IND nanoemulsion formulations and IND gel was assessed (Figure 6). All formulations exhibited anti-inflammatory activity significantly greater than the IND gel group $(P<0.05$ and $P<0.001)$. The increase in the paw volume after 4 hours following carrageenan administration in 
the control $(1.78 \pm 0.04 \mathrm{ml})$ and nanoemulsion treated groups ranged from $0.55 \pm 0.01$ to $0.96 \pm 0.05 \mathrm{ml}$, while the IND gel showed $1.16 \pm$ $0.05 \mathrm{ml}$ increases in hind paw swelling. The anti-inflammatory activity was $48,82,87$ and $98 \%$ and $10,28,41$ and $50 \%$ at $1,2,3$, and $4 \mathrm{~h}$, after administration of $F_{1}$ nanoemulsion and IND gel, respectively. The enhanced anti-inflammatory effects of true nanoemulsions could be due to the enhanced permeation of indomethacin through the skin [39].

\section{Conclusion}

Given the results of this study, it is clear that nanoemulsion formulation loaded with IND is potentially useful for permeation of IND in transdermal delivery. It is possible to conclude that, transdermal administration of IND may be considered as an alternative to iv and po administration to overcome its disadvantages. In this paper, the results suggested that the nanoemulsion played a role in permeation enhancing effect. Compared with commercial IND gel, the skin permeation ability of IND was significantly increased by nanoemulsions, which might result from the special characteristics of nanoemulsions. It is promising that the concentration of IND used to treat relative skin inflammatory conditions could be decreased due to the high permeation ability of IND nanoemulsion and side effects of IND might be reduced. Thus, the present study suggests that, transdermal administration may be considered as an alternative noninvasive method for IND delivery to achieve rapid onset of its pharmacological effect.

\section{Acknowledgements}

The authors extend their appreciation to the Deanship of Scientific Research at King Saud University for funding the work through the research group project No (RGP-VPP-039). The authors are thankful to Gattefosse, S.A., France for providing the gift samples of Labrasol and Transcutol-P.

\section{References}

1. Al-Swayeh OA, Clifford RH, del Soldato P, Moore PK (1999) A comparison of the anti-inflammatory and antinociceptive activity of nitroaspirin and aspirin. $\mathrm{Br}$ J Pharmacol 129: 343-350.

2. Artusi M, Nicoli S, Colombo P, Bettini R,Sacchi A, et al. (2004) Effect of chemical enhancers and iontophoresis on thiocolchicoside permeation across rabbit and human skin in vitro. J Pharm Sci 93: 2431-2438.

3. Baroli B, Lopez-Quintela MA, Delgado-Charro MB, Fadda, AM, BlancoMendezJ (2000)Microemulsions for topical delivery of 8-methoxsalen. J Control Release 69: 209-218.

4. Barry BW (1987) Mode of action of penetration enhancers in human skin. J Control Release 6: 85-97.

5. Barthélémy P, Farah N, Laforet JP (1995) Transcutol-product profile. Product Information. Gattefossé 1-10.

6. Burapapadh K, Kumpugdee-Vollrath M, Chantasar D, Sriamornsak P (2010) Fabrication of pectin-based nanoemulsions loaded with itraconazole for pharmaceutical application. Carbohydrate Polymers 2010: 82: 384-393.

7. Celesti L, Murratzu C, Valoti M, Sgaragli P, Corti P (1992) The single-pass perfused rabbit ear as a model for studying percutaneous absorption of clonazepam. I. General characteristics. Methods Find Exp Clin Pharmacol 14: 701-709.

8. Chang XL, Chen HB, Zhao XZ, Gao Z H, Xu HB et al. (2005) High performance liquid chromatography determination of triptolide in vitro permeation studies. Anal Chim Acta 534: 215-221.

9. Changez M, Chander J, Dinda AK (2006) Transdermal permeation of tetracaine hydrochloride by lecithin microemulsion: in vivo. Colloids Surf B Biointerf 48: 58-66.

10. Changez M, Varshney M, Chander J, Dinda AK (2006) Effect of the composition of lecithin/n-propanol/isopropyl myristate/water microemulsions on barrier properties of mice skin for transdermal permeation of tetracaine hydrochloride: In vitro. Colloids Surf. B Biointerf 50: 18-25.

11. Cevc G, Vierl U (2010) Nanotechnology and the transdermal route: A state of the art review and critical appraisal. J Control Release 141: 277-299.

12. Chen HB, Chang XL, Weng T, Zhao XZ, Gao Z, et al. (2004) A study of microemulsion systems for transdermal delivery of triptolide. J Control Release 98: 427-436.

13. Chen H, Chang X, Du D, Li J, Xu H, et al. (2006) Microemulsion-based hydrogel formulation of ibuprofen for topical delivery. Int J Pharm 315: 52-58.

14. Craig DQM, Barker SA, Banning D, Booth SW (1995) An investigation into the mechanism of self-emulsification using particle size analysis and low frequency dielectric spectroscopy. Int J Pharm 114: 103-110.

15. Delgado-Charro MB, Iglesias-Vilas G, Blanco-Mĕndez J, Lŏpez-Quintela MA Marty JP, et al. (1997) Delivery of a hydrophilic solute through the skin from novel microemulsion systems. Eur J Pharm Biopharm 43: 37-42.

16. Djordjevic L, Primorac M, Stupar M, Krajisnik D (2004) Characterization of caprylocaproyl macrogolglycerides based microemulsion drug delivery vehicles for an amphiphilic drug. Int J Pharm 271: 11-19.

17. El-Maghraby GM (2008) Transdermal delivery of hydrocortisone from eucalyptus oil microemulsion. Int J Pharm 355: 285-292.

18. Gasco MR (1997) Microemulsions in the Pharmaceutical Field. In: Perspectives and Applications, Industrial Applications of Microemulsions. Marcel Dekker Inc New Yor k 97-122

19. Gasco MR, Gallarate M, Trotta M, Bauchiero L, Gremmo E, et al. (1989) Microemulsions as topical delivery vehicles: ocular administration of timolol. J Pharm Biochem Anal 7: 433-439.

20. Gasco MR, Gallarate M, Pattarino F (1991) In vitro permeation of azelaic acid from viscosized microemulsion. Int J Pharm 69: 193-196.

21. Ghosh P K, Majithiya R J, Umrethia M L, Murthy R S R (2006) Design and Development of Microemulsion Drug Delivery System of Acyclovir for Improvement of Oral Bioavailability. AAPSPharmSciTech 7: 77.

22. Huang YB, Wu PC, Ko HM, Tsai YH (1995) Cardamon oil as a skin permeation enhancer for indomethacin, piroxicam and diclofenac. Int J Pharm 126: 111 117

23. Kreilgaard M (2002) Influence of microemulsions on cutaneous drug delivery. Adv Drug Deliv Rev 54: 77-98.

24. Kreilgaard M, Pedersen EJ, Jaroszewski JW (2000) NMR Characterisation and transdermal drug delivery potential of microemulsion systems. J Control Releas 69: $421-433$.

25. Kuminek G, Kratz JM, Ribeiro R, Kelmann RJ, de Araújo BV, et al. (2009) Pharmacokinetic study of a carbamazepine nanoemulsion in beagle dogs. Int $J$ Pharm 378: 146-148.

26. Lawrenc MJ, Rees GD (2000) Microemulsion-based media as novel drug delivery systems. Adv Drug Deliv Rev 45: 89-121.

27. Lee J, Lee Y, Kim J, Yoon M, Choi YW (2005) Formulation of microemulsion systems for transdermal delivery of aceclofenac. Arch Pharm Res 28: 10971102.

28. Lee PJ, Langer R, Shastri VP (2003) Novel microemulsion enhancer formulation for simultaneous transdermal delivery of hydrophilic and drugs. Pharm Res 20 264-269.

29. Li H, Pan WS, Li JY, Ying Z (2004) Preparation, evaluation, and NMR characterization of vinpocetine microemulsion for transdermal delivery. Drug Dev Ind Pharm 30: 657-666.

30. Li H, Pan WS, Wu Z, Li JY, Xia LX (2004) Optimization of microemulsion containing vinpocetine and its physicochemical properties. Yao Xue Xue Bao 39: $681-685$.

31. Madhusudhan B, Rambhau, D, Apte S S, Gopinath D (2007) 1-O-alkylglycero stabilized carbamazepine intravenous o/w nanoemulsions for drug targeting in mice. J Drug Target 15: 154-161. 
Citation: Barakat N, Fouad E, Elmedany A (2011) Formulation Design of Indomethacin-Loaded Nanoemulsion For Transdermal Delivery. Pharm Anal Acta S2:002. doi:10.4172/2153-2435.S2-002

Page 8 of 8

32. Mei Z N, Chen HB, Weng T, Yang YJ, Yang X (2003) Solid lipidnanoparticle and microemulsion for topical delivery of triptolide. Eur J Pharm Biopharm 56: 189-196.

33. Monteiro-Riviere NA, Inman AD, Riviere JE, McNeill SC, Francoeur ML (1993) Topical penetration of piroxicam is dependent on the distribution of the local cutaneous vasculature. Pharm Res 10: 1326-1331.

34. Nandi I, Bari M, Joshi H (2003) Study of Isopropyl Myristate Microemulsion Systems Containing Cyclo-dextrins to improve the Solubility of 2 Model Hydrophobic Drugs. AAPS PharmSciTech 4: Article 10

35. Pattarino F, Marengo E, Gasco MR (1993) Experimental design and partial least squares in the study of complex mixtures: microemulsions as drug carriers. Int J Pharm 91: 157-165.

36. Peltora S, Saarinen-Savolanien P, Kiesvaara J, Suhonen TM, Urtti A (2003) Microemulsion for topical delivery of estradiol. Int J Pharm 254: 99-107.

37. Rhee YS, Choi JG, Park ES, Chi SC (2001) Transdermal delivery of ketoprofen using microemulsions. Int J Pharm 228: 161-170.

38. Shakeel F, Baboota S, Ahuja A, Ali J, Aqil M, et al. (2007) Nanoemulsions as vehicles fro transdermal delivery of aceclofenac. AAPS pharmSciTech 8: article 104

39. Shakeel F, Ramadan W, Ahmed M A (2009) Investigation of true nanoemulsions for transdermal potential of indomethacin: Characterization rheological characteristics and ex vivo skin permeation studies. J Drug Target 17: 435441.

40. Singh P, Roberts M S (1994) Skin permeability and local tissue concentrations of nonsteroidal anti-inflammatory drugs after topical application. J Pharmacol Exp Ther 268: 144-151.

41. Sintov AC, Shapiro L (2004) New microemulsion vehicle facilitates percutaneous penetration in vitro and cutaneous drug bioavailability in vivo. J Control Release 95: 173-183.

42. Subramanian N, Ray S, Ghosal SK, Bhadra R, Moulik SP. Development and bioavailability assessment of ramipril nanoemulsion formulation. Eur J Pharm Biopharm 66: 227-243.
43. Tadros TF (1992) Future developments in cosmetic formulations. Int J Cosmet Sci 14: 93-111.

44. Takahashi K, Tamagawa S, katagi T, Yoshitomi H, Kamada A, et al. (1991) In vitro transport of sodium diclofenac across rat abdominal skin: effect of selection of oleaginous component and the addition of alcohols to the vehicle. Chem Pharm Bull 39: 154-158.

45. Tenjarla S (1999) Microemulsions: an overview and pharmaceutical applications. Crit Rev Ther Drug Carrier Syst 16: 461-521.

46. Tomšič $M$, Podlogar $F$, Gašperlin $M$, Bešter-Rogač $M$, Jamnik A (2006) WaterTween $40^{\circledR} /$ Imwitor $308^{\circledR}$-isopropyl myristate microemulsions as delivery systems for ketoprofen: Small-angle X-ray scattering study. Int J Pharm 327 $170-177$.

47. Touitou E, Dayan N, Bergelson L, Godin B, Eliaz M (2000) Ethosomes-nove vesicular carriers for enhanced delivery: characterization and skin penetration properties. J Control Release 65: 403-418.

48. Walters KA (1989) Penetration enhancers and their use in transderma therapeutic systems. In: Hadgraft J, Guy RH, eds. Transdermal Drug Delivery, Developmental Issues and Research Initiatives. New York, NY: Marcel Dekker: $197 Y 246$.

49. Winter CA (1965) Anti-inflammatory testing methods: comparative evaluation of indomethacin and other agents. Int Symp Nonst Anti-inflamm Drugs 82: 190202

50. Winter CA, Risley EA, Nuss GW (1962) Carrageenan induced edema in hind paw of the rat as an assay fro inflammatory drug. Proc Soc Exp Bio Med 111: 544-547. Yuan Y, Li SM, Mo FK, Zhong DF (2006) Investigation of microemulsion system for transdermal delivery of meloxicam. Int J Pharm 321 117-123.

51. Zhao X, Liu JP, Zhang X, Li (2006). Enhancement of transdermal delivery of theophylline using microemulsion vehicle. Int J Pharm 327: 58-64.

52. Zhu W, Yu A, Wang W, Dong R, Wu J, et al. (2008) Formulation design of microemulsion for dermal delivery of penciclovir. Int J Pharm 360: 184-190. 